\title{
Studies on the Contribution of C-fos/AP-1 to Arthritic Joint Destruction
}

\author{
Shunichi Shiozawa, Kazuhiko Shimizu, Keiichi Tanaka, and Kazuo Hino \\ Kobe University School of Medicine, Faculty of Health Science, 7-10-2 Tomogaoka, Sumaku, Kobe 654, Japan
}

\begin{abstract}
Features characteristic to rheumatoid joint destruction, including synovial overgrowth and bone resorption, are experimentally produced by augmenting c-fos gene expression. We tested here if arthritic joint destruction was inhibited upon inactivation of the c-fos/AP-1 signal by administering short double-stranded AP-1 DNA oligonucleotides into mice with collagen-induced arthritis to compete for the binding of AP-1 in vivo at the promoter binding site. Arthritic joint destruction was inhibited in a sequence-specific and dosedependent manner by oligonucleotides containing the AP-1 sequence. The oligonucleotides inhibited gene expression at the transcriptional level. Nucleotide sequences besides AP-1 also appeared to be important structurally for binding of AP-1 onto DNA and for the stability of oligonucleotides against nucleases. Immunohistochemical chase experiment administering biotinylated oligonucleotides into arthritic mice showed that AP-1 oligonucleotides reached the inflamed joint. Thus, activation of c-fos/AP-1 appears essentially important in arthritic joint destruction. (J. Clin. Invest. 1997. 99:1210-1216.) Key words: rheumatoid arthritis • synovium - bone resorption - collagen-induced arthritis • double-stranded DNA oligonucleotides
\end{abstract}

\section{Introduction}

Rheumatoid arthritis is a chronic polyarthritis of unknown etiology affecting $\sim 1 \%$ of the population worldwide (1). As to the pathogenesis of joint pain and swelling due to overgrowth of synovial tissue, osteoporosis mainly of juxtaarticular bone caused by osteoclastic bone resorption and subsequent joint deformity as a result of chronic inflammation, recent studies indicate that both antigen-centered immune response involving $\mathrm{T}$ cells and subsequent activation of synovial mesenchymal cells are essentially important (1-4). Immune response against antigens plays a central role in the initiation of rheumatoid arthritis $(1,3)$; however, the whole process of arthritic joint destruction is not explained solely by the antigen-centered immune response $(2,4)$. Synovial mesenchymal cells, as a major source of inflammatory cytokines including interleukin $1 \beta$, IL-6,

Address correspondence to Shunichi Shiozawa, Kobe University School of Medicine, Faculty of Health Science, 7-10-2 Tomogaoka, Sumaku, Kobe 654, Japan. Phone: +81-78-796-4543; FAX: +81-78991-3425. Keiichi Tanaka's present address is Research Institute, Toyama Chemical Co., 2-4-1 Shimookui, Toyama 930, Japan.

Received for publication 13 August 1996 and accepted in revised form 6 January 1997.

J. Clin. Invest.

(c) The American Society for Clinical Investigation, Inc. 0021-9738/97/03/1210/07 \$2.00

Volume 99, Number 6, March 1997, 1210-1216 and tumor necrosis factor $\alpha$, which are important in RA and as a major constituent of invasive granulation tissue called pannus, play important roles especially in the perpetuation of arthritis and subsequent joint destruction $(1,4,5)$.

We have studied the role of c-fos protooncogene in arthritis because of the importance of c-fos/c-jun heterodimer (AP-1) in regulating expression of IL-1 $\beta$, IL- $6, \mathrm{TNF} \alpha$, and collagenase, which are essentially important in RA $(1,2,6)$. In a previous study inducing experimental arthritis in $\mathrm{H} 2$-c-fos transgenic mice, we have found that overexpression of the c-fos gene leads to joint destruction without lymphocyte infiltration in which the majority of cells invading the extensively eroded joint tissue were mesenchymal synovial cells that had a potential to invade cartilage matrix when cultured in vitro (7). This is consistent with the previous finding in experimental animals that lymphocytes are not necessarily required for arthritic joint destruction $(8,9)$. Subsequent transfection studies have shown that overexpression of the c-fos gene in synovial cells potentiates growth of synovial cells (10). Overexpression of the c-fos gene in osteoblasts not only inhibited their collagen synthesis, but also stimulated osteoblasts to release factors to enhance osteoclastic bone resorption $(11,12)$. Osteoclastic bone resorption was also enhanced when the c-fos gene was overexpressed in osteoclasts (13). Synovial overgrowth and bone resorption, features characteristic to RA, are thus experimentally reproduced by augmenting c-fos gene expression. Expression of the c-fos gene is in fact increased in RA (14).

To test whether or not c-fos gene expression is essentially required for arthritic joint destruction, we tried to inhibit ongoing arthritis selectively by controlling the c-fos/AP-1 signal. Since the in vivo experiment using antisense oligonucleotides was unsuccessful in our hands, we took a new approach to administer short double-stranded AP-1 DNA oligonucleotides into mice with collagen-induced arthritis to compete for the binding of AP-1 in vivo at the promoter AP- 1 consensus binding sites. The results indicating that arthritic joint destruction is inhibited in a sequence-specific manner by the doublestranded oligonucleotides that contained the AP-1 consensus sequence are discussed in relation to the pathogenesis of rheumatoid joint destruction.

\section{Methods}

Collagen-induced arthritis. Male DBA1/J mice, 6 wk old, were purchased from Charles River Japan (Yokohama, Japan). Mice were immunize with $100 \mu \mathrm{g}$ of fetal calf type II collagen (Elastin Products Co, Owensville, MI) in CFA twice at 3-wk intervals (15). Short doublestranded 24-mer DNA oligonucleotides containing the AP-1 consensus sequence (AP-1 oligos), 5'-GTGTTACCCTGAGTCAGAGGAGAA-3' and 3'-AATGGGACTCAGTCTCCTCTTGGG-5' or the 24-mer oligonucleotides containing the sequence identical to murine collagenase (mCoAP-1 oligos) (16), 5'CACACACGCTGAGTCAGCATAAGC-3' and 3'-TGTGCGACTCAGTCGTATTCGGAC-5' were dissolved in physiological saline immediately before use and injected intraperitoneally $(0.5$ or $5 \mu \mathrm{g}$ in $0.1 \mathrm{ml}$ of saline per mouse) twice weekly starting from $14 \mathrm{~d}$ after the first immunization 
until finally examined. In some experiments, AP-1 oligos of $5 \mu \mathrm{g}$ per mouse were administered six times a week. The control oligonucleotides discordant only at the AP-1 consensus sequence (control oligos), 5'-GTGTTACCCGCCTAAGGAGGAGAA-3' and $3^{\prime}$-AATGGGCGGATTCCTCCTCTTGGG-5' were also injected in identical fashion. Sequences of 12-mer AP-1 oligos are 5'-ACCCTGAGTCAG-3' and 3'-GACTCAGTCTCC-5'.

Arthritis was evaluated from $22 \mathrm{~d}$ after the first immunization. Individual paws of mice were scored by modifying the graded scale (17) from 0 to 3: 0 , no arthritis; 1 , less than three arthritic joints of the paw; 2 , more than four arthritic joints of the paw; 3 , whole paw joints were involved. Scores obtained in two forepaws and two hindpaws were added and thus the highest score using this scale was 12 per mouse. Joints were subsequently examined for bone erosion using $\mathrm{x}$ rays at the sixth week after the first immunization. The number of bone with clear and identifiable erosion at distal ends of four metatarsal bone, tarsal bone, and tibia of the forepaw and four metacarpal bone and carpal bone of the hindpaw ( 22 joints per mouse) was assessed using soft x-ray unit (Softex, Tokyo, Japan). Joints were subsequently examined histologically at $42 \mathrm{~d}$ after the first immunization.

Undecalcified $6-\mu \mathrm{m}$-thick tissue sections, embedded in methylmethacrylate, were cut with a Jung model $\mathrm{K}$ microtome and stained with $0.05 \%$ toluidine blue ( $\mathrm{pH} 4.1$ ) for microscopic observation (7). The extent of arthritis was assessed in ankle joints according to Wooley (15): 0, normal synovium; 1 , synovial membrane hypertrophy and cell infiltrates; 2 , pannus and cartilage erosion; 3 , major erosion of cartilage and subchondral bone; 4 , loss of joint integrity and ankylosis. The extent of cell infiltration was assessed by the number of infiltrating cells per tissue slice. The mean of two joint tissue sections per mouse was expressed as: 0 , no cell infiltrates; $1,<50$ cells; $2,<200$ cells; $3,<500$ cells; $4,>500$ cells. The extent of joint destruction was assessed by the proportion of noneroded cartilage surface. The mean of two joint tissue sections per mouse was expressed as; 0 , all intact cartilage; 1 , more than two thirds intact cartilage; 2 , more than one third intact cartilage; 3 , less than one third intact cartilage; 4 , no intact cartilage. Infiltrated cells were observed morphologically or histochemically after the staining with antibodies against CD3, CD4, and CD8 (Tago Inc., Burlingame, CA) as described (7).

Immunoassay of antibodies to collagen. The level of serum antibodies to collagen was measured by ELISA (18). The microtiter plate (Sumitomo Bakelite Co., Tokyo, Japan) was coated with bovine type II collagen $(2.5 \mu \mathrm{g} / 50 \mu \mathrm{l}$ per well $)$ at $37^{\circ} \mathrm{C}$ for $1 \mathrm{~h}$. After washing with PBS containing $0.05 \%$ Tween-20, nonspecific binding was blocked with PBS containing $1 \%$ BSA for $1 \mathrm{~h}$. After three washes, serum samples were added in serial dilution and incubated at $37^{\circ} \mathrm{C}$ for $1 \mathrm{~h}$. After four washes, peroxidase-conjugated goat anti-mouse $\operatorname{IgG}$ (Tago Inc.) was added and incubated at $37^{\circ} \mathrm{C}$ for $1 \mathrm{~h}$. Antibody binding was measured using $o$-phenylenediamine (Sigma Chemical Co., St. Louis, MO) and $0.012 \% \mathrm{H}_{2} \mathrm{O}_{2}$ at $490 \mathrm{~nm}$ in a microplate reader (Bio-Rad Laboratories, Hercules, CA) (18). A standard serum, mixture of sera from arthritic mice, was added to each plate in serial dilutions, and a standard curve was calculated from these results. The result was expressed in relation to the standard serum $(100 \mathrm{U} / \mathrm{ml})$.

Reverse transcription-PCR. Knee joint synovia of mice were removed surgically by anterior approach under magnified stereoscope: the anterior ligament was incised perpendicularly to the leg. The thickened inflammatory synovium including fad pad tissue occupying the joint space was then dissected from joint capsule, tendon, and muscle by surgical knife. Synovia were immediately immersed in $1 \mathrm{ml}$ Isogen guanidium thiocyanate solution (Nippon Gene Co., Ltd., Toyama, Japan) and snap frozen in liquid nitrogen. Total RNA was isolated from joint synovia by homogenization in Isogen guanidium thiocyanate (19). The mRNA was quantified using Amplisensor assay (Biotronics Technology Corp., St. Lowell, MA). RNA was reverse transcribed in a $20-\mu \mathrm{l}$ reaction containing $2.5 \mu \mathrm{M}$ of random hexamer, $5 \mathrm{mM} \mathrm{MgCl}$, $1 \times$ PCR buffer II, $1 \mathrm{mM}$ each of dATP, dCTP, dGTP, and dTTP, $1 \mathrm{U} / \mu \mathrm{l}$ RNase inhibitor and sample mRNA at $37^{\circ} \mathrm{C}$ for $20 \mathrm{~min}$. After adding $2.5 \mathrm{U} / \mu \mathrm{l}$ Moloney murine leukemia virus re- verse transcriptase, this was further incubated at $42^{\circ} \mathrm{C}$ for $40 \mathrm{~min}, 99^{\circ} \mathrm{C}$ for $5 \mathrm{~min}$, and $4^{\circ} \mathrm{C}$ for $5 \mathrm{~min}$ (mRNA solution). To quantitate mRNA, an $8-\mu \mathrm{l}$ reaction containing mRNA solution, $1 \mathrm{mM}$ each of dCTP, dTTP, dATP, and dGTP, $5 \mathrm{mM} \mathrm{MgCl} 2,1 \times$ PCR buffer II, $5 \mathrm{ng}$ of upstream primer, $0.75 \mathrm{ng}$ of downstream primer, and $0.5 \mathrm{U}$ of AmpliTaq DNA polymerase (Perkin-Elmer Corp., Norwalk, CT) was amplified at $94^{\circ} \mathrm{C}$ for $20 \mathrm{~s}, 55^{\circ} \mathrm{C}$ for $20 \mathrm{~s}$, and $72^{\circ} \mathrm{C}$ for $30 \mathrm{~s}$ for 20 cycles. After this asymmetric preamplification, each $4 \mu \mathrm{l}$ of Amplisensor DNA primer containing donor and acceptor fluorophores in conjunction with target-specific oligonucleotide sequence was added. PCR reaction was continued for different cycles and the extent of energy transfer was assayed in a Minilyser (Biotronics Technology Corp.) to quantify primer-mediated extension by Taq polymerase in relation to disruption of duplex formation between fluorophore-labeled oligonucleotide duplex. All matrix metalloproteinases (MMPs) ${ }^{1}$ whose nucleotide sequences have so far been identified were examined in the synovium of mice obtained $6 \mathrm{~h}$ after administration of oligonucleotides.

Mouse IL- $1 \beta$-specific primer sequences were: 5 '-CTGCTGGTGTGTGACGTTCCC-3' (sense) and 5'-AGGAAGACACAGATTCCATGG-3' (antisense) (20). Mouse IL-6-specific primers were: 5'-CCCAACAGACCTGTCTATACC-3' (sense) and 5'-CAGCTTATCTGTTAGGAGAGC-3' (antisense) (21). Mouse TNF $\alpha$-specific primers were: 5'-TCGAGTGACAAGCCTGTAGCC-3' (sense) and 5'-TGACTCCAAAGTAGACCTGCC-3' (antisense) (22). Mouse $72 \mathrm{kD}$ type IV collagenase (MMP-2)-specific primers were: $5^{\prime}$-CCTCCTACAACAGCTGTA-3' (sense) and 5'-AGTACCAGTGTCAGTATC-3' (antisense) (23). Mouse stromelysin1 (MMP-3)-specific primers were: $5^{\prime}$-CTCCAACACTATGGAGCT-3' (sense) and 5'-TCCAGGTGCATAGGCATG-3' (antisense) (24). Mouse $92 \mathrm{kD}$ type IV collagenase (MMP-9)-specific primers were: 5'-ACCGCTATGGTTACACC-3' (sense) and 5'-GCAGGCCGAATAGGAGCG-3' (antisense) (25). Mouse glyceraldehyde-3-phosphate-dehydrogenase (G3PDH)-specific primers for internal control were: 5'-TTCACCACCATGGAGAAGGC-3' (sense) and 5'-AGTGATGGCATGGACTGTGG-3' (antisense) (26).

The Amplisensor primer was designed within $30 \mathrm{bp}$ from each 5' primer. IL-1 $\beta$-specific primer sequence was: $5^{\prime}$-GGGACGCGTTGTTCATCTCGGAGCCTGT-3'. IL-6-specific primer is: 5' -GGGACGCCATGTGTAATTAAGCCTCCGA-3'. TNF $\alpha$-specific primer was: 5'-GGGACGCTGCTCCTCCACTTGGTGGTTT-3'. MMP2-specific primer was: 5'-GGGACGCGTGGTGCCACACCAGCGGTAG-3'. MMP-3-specific primer is: 5'-GGGACGCAAGCCACCAACATCAGGAACA-3'. MMP-9-specific primer was: 5'-GGGACGCGGCCGTAGAGACTGCTTCTCT-3'. The Amplisensor assay (Biotronics Technology Corp.) was based on the coamplification of relevant genes by PCR (27) and fluorescence energy transfer between complementary DNA strands labeled with donor and acceptor fluorophores in which energy transfer was facilitated when the strands were basepaired, but it was eliminated when basepairing was disrupted (28). The mRNA in each sample was normalized by quantifying coamplified G3PDH mRNA.

CAT assay. $1 \mathrm{ml}$ of $2 \times 10^{6}$ murine National Institutes of Health (NIH) H-ras cells (29) in TBS $(25 \mathrm{mM}$ Tris, $137 \mathrm{mM} \mathrm{NaCl}, 5 \mathrm{mM}$ $\mathrm{KCl}, 0.6 \mathrm{mM} \mathrm{Na}_{2} \mathrm{HPO}_{4}, 0.7 \mathrm{mM} \mathrm{CaCl}, 0.5 \mathrm{mM} \mathrm{MgCl}_{2}, \mathrm{pH} 7.4$ ) was gently mixed with $1 \mathrm{ml}$ of $1 \mathrm{mg} / \mathrm{ml}$ of DEAE-dextran solution in TBS containing $50 \mu \mathrm{g}$ of Col-TRE/TK chloramphenicol acetyltransferase (CAT) reporter plasmid. The mixture was incubated at room temperature for $30 \mathrm{~min}$. Col-TRE/TK CAT kindly provided by Dr. Michael Karin contained the AP-1 oligonucleotide sequence from -71 to -65 of the human collagenase gene, which was flanked by Hind III/Bam $\mathrm{H} 1$ linker sequences and cloned into the Hind III/Bam H1 site of pBL-CAT2 bacterial CAT plasmid (30). After washing, cells $(2.5 \times$ $10^{5} / \mathrm{ml}$ ) were placed in $35-\mathrm{mm}$ dishes and cultured in the presence or

1. Abbreviations used in this paper: CAT, chloramphenicol acetyltransferase; G3PDH, glyceraldehyde-3-phosphate-dehydrogenase; MMP, matrix metalloproteinase. 
absence of AP-1 oligonucleotides at $37^{\circ} \mathrm{C}$ for $60 \mathrm{~h}$. The doublestranded DNA oligonucleotides, used in addition to AP-1 oligos and control oligos in this CAT assay, were shorter forms of AP-1 oligos: AP-1m oligos, 5' -CCCTGAGTCAGA- $3^{\prime}$, 3'-GGGACTCAGTCT-5'; and AP-1s oligos, 5' -CTGAGTCA-3' ${ }^{\prime}, 3^{\prime}$-GACTCAGT-5'

The 24-mer DNA oligonucleotides whose nucleotide sequence around the AP- 1 consensus sequence as well as TGAGTCA was identical to the promoter of CAT plasmid (catAP-1 oligos) were: $5^{\prime}$-GTAGCTTGATGAGTCAGCCGAGAA-3', and 3'-CGAACTACTCAGTCGGCTCTTGGG-5'.

The 24-mer oligonucleotides that had a sequence identical to the CAT plasmid sequence except for the AP-1 consensus site (cat-nonAP-1 oligos) were: 5'-GTAGCTTGAGCGTATGGCCGAGAA-4', and 3'-CGAACTCGCATACCGGCTCTTGGG-5'.

The CAT activity in the cell extract was determined using radioactive CAT assay (31) or CAT ELISA assay (Boehringer Mannheim, Mannheim, Germany) (32), and the result between both assays was normalized by introducing internal standards. In the radioactive CAT assay, results were quantified by cutting out the bands containing unreacted $\left[{ }^{14} \mathrm{C}\right]$ chloramphenicol and its acetylated forms and determining the amount of radioactivity by liquid scintillation counting. In CAT ELISA assay, after lysis of transfected cells, cell extracts that contain CAT enzyme were added to the microtiter plates coated with anti-CAT antibodies. The digoxigenin-labeled antibody to CAT was then added. After washing, the plates are reacted with peroxidaselabeled antidigoxigenin antibody. This was then reacted with the ABTS (2,2'-Azino-bis 3-ethylbenzthiazoline-6-sulfonic acid) substrate solution containing substrate enhancer (Boehringer Mannheim), and the activity of peroxidase enzyme was quantified using a microtiter plate reader.

Biotinylated AP-1 DNA oligonucleotide. Biotin was incorporated into oligonucleotides using Biotin-On ${ }^{\mathrm{TM}}$ phosphoamidite (Clontech Laboratories, Inc., Palo Alto, CA). Biotin-On ${ }^{\mathrm{TM}}$ was incorporated in place of the thymidine situated in the $5^{\prime}$ end of the TCAGTCA core sequence, thus producing biotinylated 5'-GTGTTACCC-(biotin)GAGTCAGAGGAGAA- $3^{\prime}$. After annealing with the corresponding $3^{\prime}$-AATGGGACTCAGTCTCCTCTTGGG-5', $100 \mu \mathrm{g}$ of this DNA was administered intraperitoneally into DBA1/J male mice immunized with collagen in identical fashion to the induction of collagen-induced arthritis. The shorter 12-mer biotinylated doublestranded DNA composed of 5'-CC-(biotin)-CAGTCAGAG-3' and the corresponding $3^{\prime}$-GGAGTCAGTCTC-5' or single thymidine nucleotides (biotin-d ${ }^{\mathrm{TM}}$ ) was also injected. Knee joint synovial tissues of mice were removed surgically by anterior approach under magnified stereoscope 6 and $24 \mathrm{~h}$ after the intraperitoneal injection: the anterior ligament was incised perpendicularly to the leg. The thickened inflammatory synovium including fad pad tissue occupying the joint space was then dissected from joint capsule, tendon, and muscle using a surgical knife. Synovia were immediately immersed in $4 \%$ paraformaldehyde and snap frozen in liquid nitrogen. Cryostat sections $6-\mu \mathrm{m}$ thick were reacted with fluorescein-avidin conjugates (Vector Laboratories, Inc., Burlingame, CA) and observed in a fluorescent microscope.

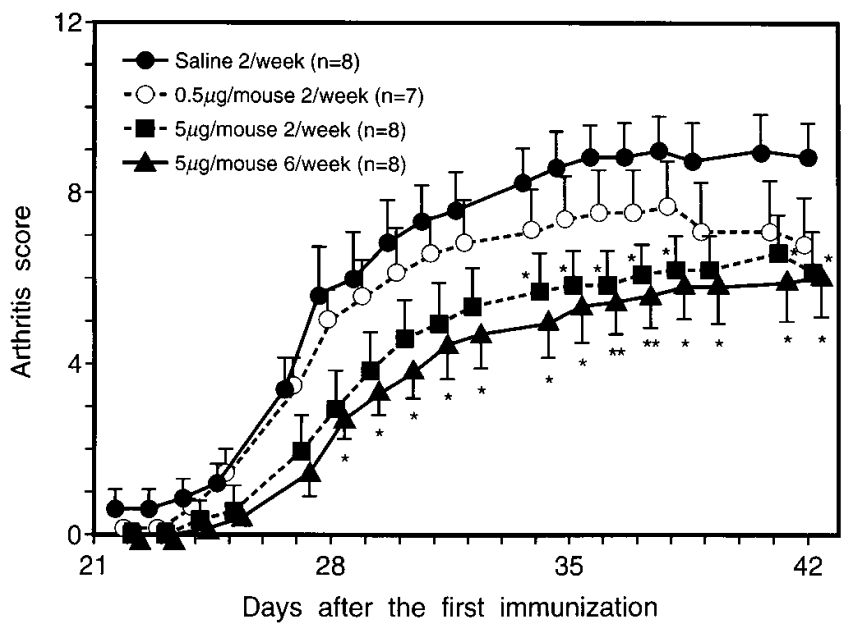

Figure 1. Collagen-induced arthritis in DBA1/J mice. Arthritis score is measured from $22 \mathrm{~d}$ after the first immunization until finally examined. Individual paws of mice are scored by modifying graded scale (17) from 0 to 3: 0 , no arthritis; 1 , less than three arthritic joints of the paw; 2 , more than four arthritic joints of the paw; 3 , whole paw joints are involved. Scores obtained in two forepaws and two hindpaws are added and thus the highest score is 12 per mouse. Values shown are mean \pm SEM. $* P<0.05, * * P<0.01$ by Student's nonpaired $t$ test.

\section{Results}

Collagen-induced arthritis. We followed a previously established protocol of collagen-induced arthritis to induce experimental arthritis in DBA1/J male mice (15). Mice were immunized with fetal calf type II collagen twice at 3-wk intervals. Short double-stranded DNA oligonucleotides containing AP-1 sequence (AP-1 oligos) or control DNA oligonucleotides of the same length discordant only at the AP-1 consensus sequence (control oligos) were administered intraperitoneally twice weekly starting from 14 to $42 \mathrm{~d}$ after the first immunization until joints of mice were finally examined.

Arthritis score of mice was decreased by the administration of AP-1 oligos in a dose-dependent manner (Fig. 1). Table I shows the incidence of arthritis in which the number of mice with arthritis of more than grade 1 degree of the modified graded scale (17) was enumerated: onset of arthritis was slightly retarded by the treatment with AP-1 oligos. Joint erosion as examined with $\mathrm{x}$ rays was also decreased by the administration of AP-1 oligos: the number of juxtaarticular bone with clear and identifiable erosion of the paw of mice receiving 0.5

Table I. Effect of Double-stranded AP-1 DNA Oligonucleotides on the Incidence of Collagen-induced Arthritis of the DBA1/J Male Mice in Fig. 1

\begin{tabular}{|c|c|c|c|c|c|c|c|c|c|c|c|}
\hline \multirow{2}{*}{$\begin{array}{l}\text { Oligonucleotide } \\
\text { Saline }\end{array}$} & & \multicolumn{2}{|c|}{ Treatment } & \multirow{2}{*}{$\frac{21^{*}}{0 / 8^{\ddagger}}$} & \multirow{2}{*}{$\frac{22}{2 / 8}$} & \multirow{2}{*}{$\frac{23}{2 / 8}$} & \multirow{2}{*}{$\begin{array}{l}24 \\
3 / 8\end{array}$} & \multirow{2}{*}{$\frac{25}{5 / 8}$} & \multirow{2}{*}{$\frac{27}{8 / 8}$} & \multirow[t]{2}{*}{28} & \multirow[t]{2}{*}{29} \\
\hline & & $2 / \mathrm{wk}$ & $(n=8)$ & & & & & & & & \\
\hline AP-1 & $0.5 \mu \mathrm{g} / \mathrm{mouse}$ & $2 / w k$ & $(n=7)$ & $0 / 7$ & $1 / 7$ & $1 / 7$ & $4 / 7$ & $4 / 7$ & $6 / 7$ & $7 / 7$ & \\
\hline AP-1 & $5 \mu \mathrm{g} / \mathrm{mouse}$ & $2 / \mathrm{wk}$ & $(n=8)$ & $0 / 8$ & $0 / 8$ & $0 / 8$ & $1 / 8$ & $2 / 8$ & $5 / 8$ & $6 / 8$ & $8 / 8$ \\
\hline AP-1 & $5 \mu \mathrm{g} / \mathrm{mouse}$ & $6 /$ wk & $(n=8)$ & $0 / 8$ & $0 / 8$ & $0 / 8$ & $1 / 8$ & $3 / 8$ & $4 / 8$ & $8 / 8$ & \\
\hline
\end{tabular}

The number of mice with arthritis of more than grade 1 degree of the modified grade scale (17) is enumerated. * Days after the first immunization with collagen. ${ }^{\ddagger}$ The number of mice with arthritis in at least one joint vs. the total number of mice. 
Table II. Histologic Study of the Effect of Double-stranded AP-1 DNA Oligonucleotides on Collagen-induced Arthritis of the DBA1/J Male Mice in Fig. 1

\begin{tabular}{|c|c|c|c|c|c|c|}
\hline \multirow{2}{*}{$\begin{array}{l}\text { Oligonucleotide } \\
\text { Saline }\end{array}$} & & \multicolumn{2}{|c|}{ Treatment } & \multirow{2}{*}{$\frac{\text { Arthritis }}{3.25 \pm 1.17^{\ddagger}}$} & \multirow{2}{*}{$\frac{\text { Cell infiltration }}{3.50 \pm 1.07^{\ddagger}}$} & \multirow{2}{*}{$\frac{\text { Joint destruction }}{3.36 \pm 1.06^{\ddagger}}$} \\
\hline & & $2 / w k$ & $(n=8) *$ & & & \\
\hline AP-1 & $0.5 \mu \mathrm{g} / \mathrm{mouse}$ & $2 / w k$ & $(n=7)$ & $2.14 \pm 1.07^{\S}$ & $3.01 \pm 1.00^{\S}$ & $2.14 \pm 1.57^{\S}$ \\
\hline AP-1 & $5 \mu \mathrm{g} / \mathrm{mouse}$ & $2 / w k$ & $(n=8)$ & $1.88 \pm 0.99 \|$ & $2.75 \pm 1.17 \|$ & $1.50 \pm 1.19 \|$ \\
\hline \multirow[t]{4}{*}{ AP-1 } & $5 \mu \mathrm{g} /$ mouse & $6 / \mathrm{wk}$ & $(n=8)$ & $1.50 \pm 1.31^{\llbracket}$ & $2.87 \pm 1.36^{\pi}$ & $1.38 \pm 1.41^{\llbracket}$ \\
\hline & & & & $(P=0.04)^{q-\S}$ & $(P=0.1)^{\ddagger-\S}$ & $(P=0.05)^{\ddagger-\S}$ \\
\hline & & & & $(P=0.01)^{\ddagger-\|}$ & $(P=0.1)^{\ddagger-\|}$ & $(P=0.002)^{\ddagger-\|}$ \\
\hline & & & & $(P=0.006)^{\ddagger-\pi}$ & $(P=0.16)^{\ddagger-\pi}$ & $(P=0.003)^{\ddagger-\pi}$ \\
\hline
\end{tabular}

The mean score of the two ankle joints per mouse is added and statistically analyzed. *The number of mice. Statistical analyses (mean \pm SD) by the Student's nonpaired $t$ test. ${ }^{\ddagger-\S},{ }^{*-\|}$, or ${ }^{\ddagger-\pi}$, the difference between ${ }^{\ddagger}$ and $\$$, $\|$, or $\mathbb{\pi}$, respectively.

$\mu \mathrm{g}$ of AP-1 oligos twice a week was $8.9 \pm 4.9($ mean $\pm \mathrm{SD})(n=8)$, those receiving $5 \mu \mathrm{g}$ of AP-1 oligos twice a week was 7.9 \pm 5.0 $(n=7)$, and those receiving $5 \mu \mathrm{g}$ of AP-1 oligos six times a week was $6.1 \pm 3.9(n=8)$. Those receiving $5 \mu \mathrm{g}$ of AP-1 oligos six times a week showed statistically significant improvement as compared with $10.8 \pm 1.7$ of mice receiving control oligos $(P<0.05)$. Detailed histological examination of the ankle joints of mice tested in Fig. 1 shows that arthritis and joint destruction of mice were significantly modified by the treatment with AP-1 oligos in a dose-dependent manner (Table II). Arthritis score of mice was not significantly decreased by the treatment with $5 \mu \mathrm{g}$ 12-mer AP-1 oligos twice a week $(n=8)$ (not shown).

In a separate experiment, we tried to dissect the mode of action of AP-1 oligos more precisely. Histological examination of the ankle joints of mice receiving oligonucleotides twice a week revealed that arthritis, inflammatory cell infiltration and joint destruction were improved by the treatment with AP-1 oligos as compared with those left untreated or those treated with control oligos (Table III). Serum levels of anticollagen antibodies, quantified as a measure of cellular change in the arthritic mice in experiment 2, were $100 \pm 58.1 \mathrm{U} / \mathrm{ml}$ in mice treated with control oligos $(n=12)$ and $66.4 \pm 50.2 \mathrm{U} / \mathrm{ml}$ in mice treated with AP-1 oligos $(n=14)$, and this was statistically significant $(P=0.025)$. Routine morphological or his- tochemical observation employing anti-CD3, anti-CD4, or anti-CD8 antibodies showed that AP-1 oligos appeared not to change the distribution and composition of cellular infiltrates to the joints significantly (not shown). In contrast, it was noted in Table III that improvement of joint destruction was highly significant as compared with those of inflammatory cell infiltration, which was consistent with the result obtained in Table II. Measurement of mRNAs for cytokines and matrix-degrading enzymes, important for arthritic joint destruction, in the knee joint synovia of mice using reverse transcription-PCR revealed that mRNAs for IL-1 $\beta$, IL-6, TNF $\alpha$, stromelysin1 (MMP-3), and $92 \mathrm{kD}$ type IV collagenase (MMP-9) were reduced in mice receiving AP-1 oligos as compared with mice receiving control oligos (Fig. 2). However, mRNA for MMP-2, which did not contain the AP-1 sequence in its promoter, was not decreased by the treatment with AP-1 oligos.

We next administered mCoAP-1 oligos containing the AP-1 sequence completely identical to the promoter region of murine collagenase to compete for the binding of AP- 1 in vivo at the promoter AP-1 sequence of collagenase. It was found that joint destruction, but not inflammatory cell infiltration, was more significantly inhibited by mCoAP-1 oligos as compared with those treated with AP-1 oligos (Table III).

The change of body weight during the study period was $151 \%$ in mice treated with AP-1 oligos $(n=14)$ and was $144 \%$

Table III. Histologic Study of the Effect of DNA Oligonucleotides on Collagen-induced Arthritis of DBA1/J Male Mice

\begin{tabular}{|c|c|c|c|c|c|}
\hline \multirow{2}{*}{$\frac{\text { Experiment }}{1}$} & \multicolumn{2}{|c|}{ Oligonucleotide } & \multirow{2}{*}{$\begin{array}{c}\text { Arthritis } \\
3.18 \pm 1.11\end{array}$} & \multirow{2}{*}{$\begin{array}{c}\text { Cell infiltration } \\
3.44 \pm 1.09\end{array}$} & \multirow{2}{*}{$\frac{\text { Joint destruction }}{2.79 \pm 1.05}$} \\
\hline & Nil & $(n=16)^{*}$ & & & \\
\hline & AP-1 & $(n=14)$ & $\begin{array}{r}1.92 \pm 1.33 \\
(P=0.009)\end{array}$ & $\begin{array}{c}2.64 \pm 0.92 \\
(P=0.02)\end{array}$ & $\begin{array}{r}1.44 \pm 1.21 \\
(P=0.003)\end{array}$ \\
\hline 2 & Control $^{\ddagger}$ & $(n=12)$ & $3.08 \pm 1.08$ & $3.07 \pm 0.79$ & $2.80 \pm 0.80$ \\
\hline & AP-1 & $(n=14)$ & $\begin{array}{l}2.07 \pm 1.21 \\
(P=0.03)\end{array}$ & $\begin{array}{c}2.28 \pm 0.91 \\
(P=0.02)\end{array}$ & $\begin{array}{r}1.42 \pm 1.44 \\
(P=0.009)\end{array}$ \\
\hline 3 & Control & $(n=16)^{\S}$ & $3.06 \pm 1.12$ & $3.44 \pm 0.73$ & $3.38 \pm 1.09$ \\
\hline & AP-1 & $(n=16)^{\|}$ & $1.93 \pm 1.29$ & $2.50 \pm 1.55$ & $2.38 \pm 1.26$ \\
\hline & mCoAp-1 & $(n=16)^{\pi}$ & $\begin{array}{c}1.38 \pm 1.31 \\
(P=0.01)^{\S-\|} \\
(P=0.003)^{\|-\pi}\end{array}$ & $\begin{array}{c}1.81 \pm 1.51 \\
(P=0.05)^{\S-\|} \\
(P=0.4)^{\|-\pi}\end{array}$ & $\begin{array}{c}1.06 \pm 1.06 \\
(P=0.004)^{\S-\|} \\
(P=0.04)^{\|-\Phi}\end{array}$ \\
\hline
\end{tabular}

The mean score of the two ankle joints per mouse is added and statistically analyzed. Experiments 1,2 , and 3 are done separately but simultaneously in a group. *The number of mice. ${ }^{\ddagger}$ Control oligonucleotides. Statistical analyses (mean \pm SD) by the Student's $t$ test. ${ }^{\S} \|$ or ${ }^{\|-\pi}$, the difference between ${ }^{\S}$ and ${ }^{\|}$or ${ }^{\|}$and ${ }^{\mathrm{T}}$, respectively. 


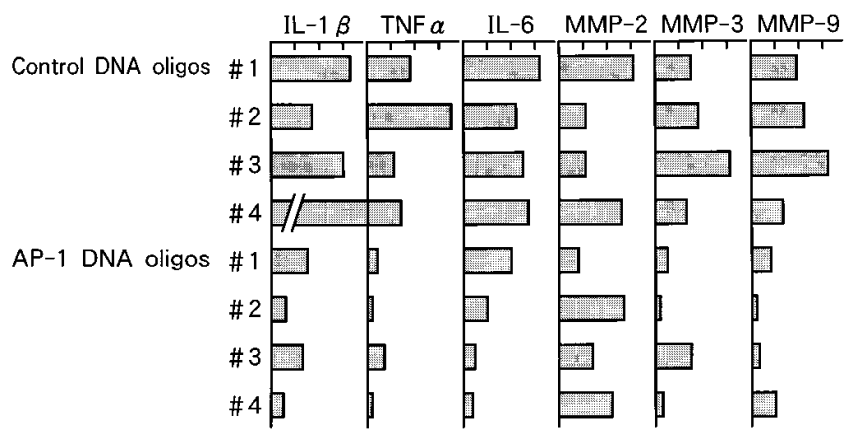

Figure 2. Quantification of mRNA for cytokine and matrix metalloproteinase in synovia of mice treated with AP-1 DNA oligos or control DNA oligos. mRNA of mice is reversibly transcribed and coamplified relevant genes are quantified with reference to coamplified G3PDH mRNA using Amplisensor assay. The amount of mRNA is expressed with an arbitrary scale for individual cytokines and MMPs using serial dilution of one representative sample as standard. The differences between two groups, except for MMP-2 and IL-1 $\beta$, are $<0.02$, and those of IL- $1 \beta$ are $<0.06$ by the Student's nonpaired $t$ test.

in mice treated with control oligos $(n=12)$. There were no significant changes in circulating blood cell counts or in serum levels of total protein, albumin, glutamic oxaloacetic transaminase, glutamic pyruvic transaminase, alkaline phosphatase, lactic dehydrogenase, urea nitrogen, creatine, glucose, total cholesterol, and triglyceride between the groups. The change of the weight of thymus, spleen, and mesenteric lymph nodes was also insignificant. This was also the case for the mice treated with $5 \mu \mathrm{g}$ of AP-1 oligos six times per week $(n=8)$ (not shown).

Transfection study. To test if AP-1 oligos acted at the level of gene transcription, Col-TRE/TK CAT containing an AP-1

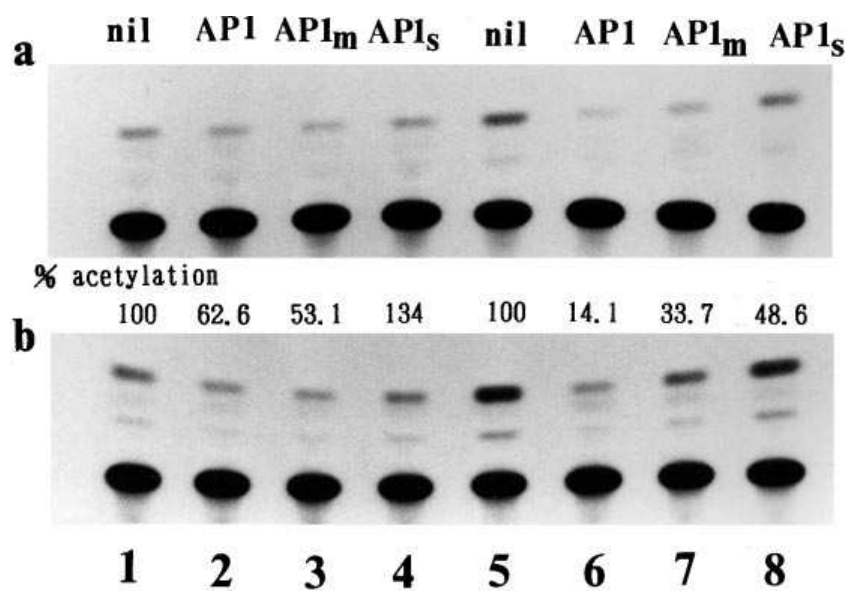

Figure 3. Radioactive CAT assay for $2(a)$ and $5 \mathrm{~h}(b)$ for Col-TRE/ TK CAT activity. Short double-stranded DNA oligos are added to cultured murine NIH H-ras cells (29) transfected with Col-TRE/TK CAT every $12 \mathrm{~h}$ at $2 \mu \mathrm{g} / \mathrm{ml}$ (lanes $1-4$ ) and $20 \mu \mathrm{g} / \mathrm{ml}$ (lanes 5-8). Cell culture of samples in lanes 1-4 and those in lanes 5-8 are done separately, with CAT assay performed simultaneously. Percent acetylation at $5 \mathrm{~h}$ is quantified and expressed by cutting out the bands containing unreacted $\left[{ }^{14} \mathrm{C}\right]$ chloramphenicol and its acetylated forms and determining the amount of radioactivity. Protein concentration of cell extracts is adjusted using Bio-Rad reagent. consensus cassette fused to a CAT reporter gene was transfected into H-ras-transformed NIH3T3 cells (NIH H-ras cells) that constitutively expressed AP-1 (29). The cells were cultured for $60 \mathrm{~h}$ in the presence of different types of oligonucleotides. It was found that AP-1s oligos containing only the AP-1 core sequence were weak at inhibiting gene transcription, while gene transcription through the AP-1 promoter site was more significantly inhibited in a dose-dependent manner by the longer oligonucleotides, AP-1 oligos, or AP-1m oligos, that contained additional nucleotide sequences (Fig. 3).

Since the result indicated either that shorter oligonucleotides were easily degradable by nucleases in the cell or that a nucleotide sequence besides the AP-1 core sequence was necessary for effective binding of AP-1 to DNA, we next compared the effect of double-stranded 24-mer oligonucleotides with a different nucleotide sequence (Fig. 4). The catAP-1 oligos, composed of the 24-mer nucleotide sequence completely identical to the Col-TRE/TK CAT promoter sequence, were most potent in inhibiting gene transcription, whereas the AP-1 oligos, identical only at the AP-1 consensus sequence, were next in the ability to inhibit gene transcription. Either cat nonAP-1 oligos discordant only at the core AP-1 consensus sequence or totally discordant control oligos did not inhibit gene transcription.

Administration of labeled oligonucleotides. To examine whether or not administered DNA oligonucleotides reached the joint and could exert biological effects in vivo, the AP-1 oligonucleotide that contained a biotin-tag in place of the thymidine at the 5' end of TGAGTCA core sequence was administered intraperitoneally into mice with collagen-induced arthritis. It was found that cytoplasm and nuclei of the cell of knee joints were positively stained $6 \mathrm{~h}$ after the intraperitoneal injection of biotinylated AP-1 oligonucleotides (Fig. 5, $a$ and $b$ ). The staining faded $24 \mathrm{~h}$ after the injection (not shown). The cells were not stained when shorter 12-mer AP-1 oligonucleotides or single thymidine oligonucleotides were administered (Fig. 5, $c$ and $d$ ).

\section{Discussion}

The result showed that short double-stranded DNA oligonucleotides containing the AP-1 consensus sequence modified

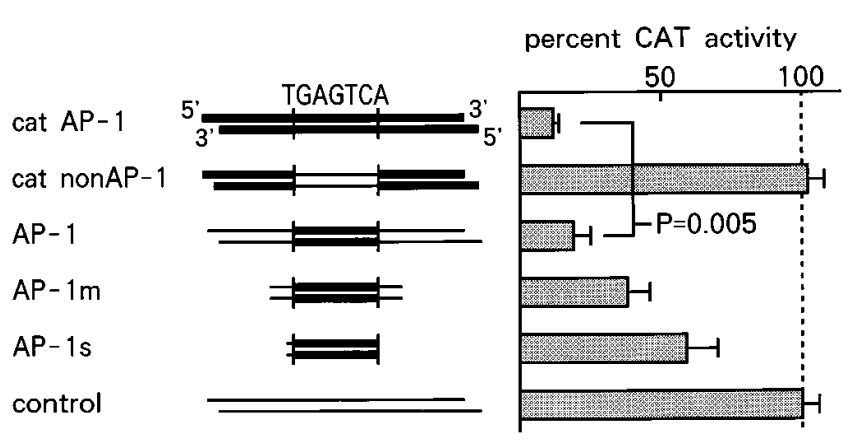

Figure 4. Percent CAT activity when different DNA oligonucleotides are added to cultured NIH H-ras cells (29) transfected with Col-TRE/ TK CAT every $12 \mathrm{~h}$ at $20 \mu \mathrm{g} / \mathrm{ml}$. Thick line indicates the area of nucleotide sequence that is identical to the promoter region of ColTRE/TK CAT plasmid. Values shown are mean \pm SD of three experiments. 


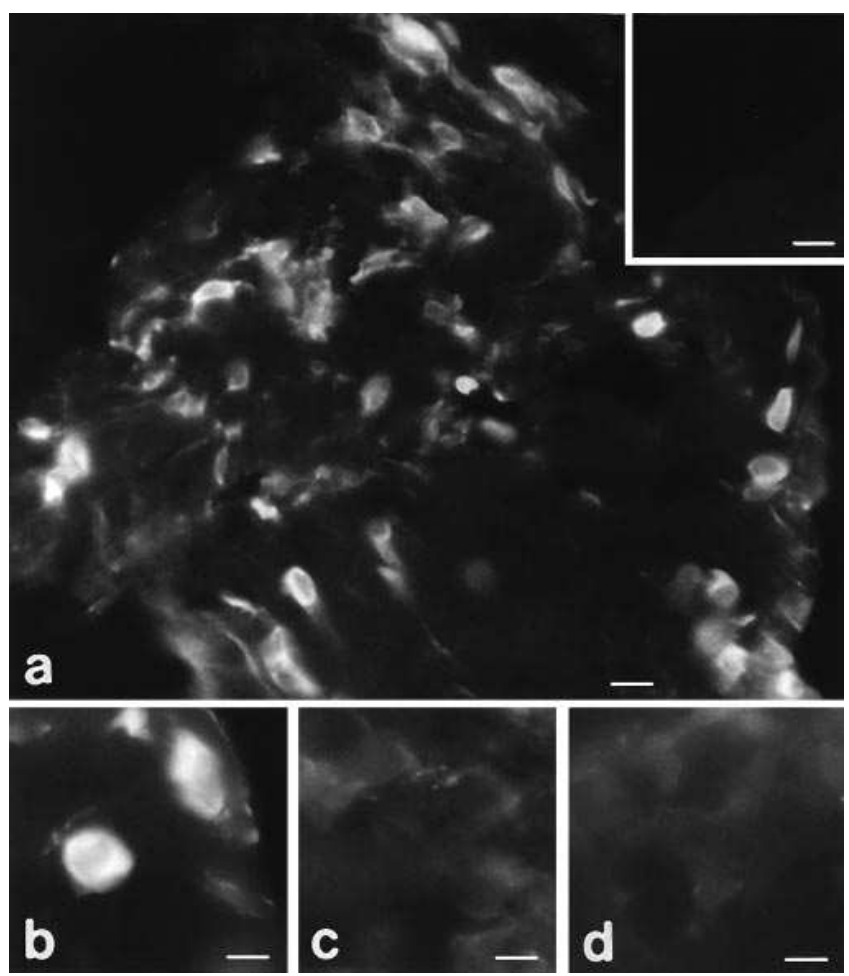

Figure 5. Immunofluorescent staining of knee joint synovia for biotinylated oligonucleotides. (a) Double-stranded AP-1 oligonucleotides 5'-GTGTTACCC-(biotin)-GAGTCAGAGGAGAA-3' in conjunction with corresponding 3 '-AATGGGACTCAGTCTCCTCTTGGG-5' $(100 \mu \mathrm{g})$ are administered intraperitoneally into hyperimmunized DBA1/J male mice. Knee joint synovia obtained $6 \mathrm{~h}$ after the intraperitoneal injection are stained with fluorescein-avidin. Inset, control section without fluorescein-avidin. Original magnification 100. Scale bar $=20 \mu \mathrm{m}$. (b) Magnified view of synovium similar to $a$. Original magnification 200. Scale bar $=10 \mu \mathrm{m}$. (c) Synovia obtained $6 \mathrm{~h}$ after the injection $(70 \mu \mathrm{g})$ of shorter DNA composed of 5 '-CC-(biotin)-CAGTCAGAG-3' and the corresponding 3'-GGAGTCAGTCTC-5. Stained with fluorescein-avidin in identical fashion to $a$. Original magnification 200. Scale bar $=10 \mu \mathrm{m} .(d)$ Synovia obtained $6 \mathrm{~h}$ after the injection $(20 \mu \mathrm{g})$ of single nucleotides Biotin- $\mathrm{dT}^{\mathrm{TM}}$. Stained in identical fashion to $a$. Original magnification 200. Scale bar $=10 \mu \mathrm{m}$.

collagen-induced arthritis in a sequence-specific and dosedependent manner. Arthritis became less severe when an increased amount of AP-1 oligos was administered. However, the onset of arthritis was only slightly retarded by the treatment with AP-1 oligos, suggesting that AP-1 oligos do not appear to protect mice from developing arthritis significantly. This is interesting in relation to the contribution of c-fos/AP-1 to joint destruction, the later manifestation of arthritis. The finding that $\mathrm{mCoAP}-1$ oligos containing the sequence identical to the promoter AP-1 region of murine collagenase, the enzyme that is essentially important in joint destruction $(1,2)$, efficiently inhibited joint destruction suggests that nucleotide sequences besides the AP-1 sequence are also important structurally for efficient binding of AP-1 transcription factor onto DNA. This is in agreement with the result of the transfection study using Col-TRE/TK CAT in which catAP-1 oligos whose nucleotide sequence was completely identical to the Col-TRE/ TK CAT promoter sequence were more potent than AP-1 oli- gos, which were identical only at the AP-1 consensus sequence, in inhibiting gene transcription. Immunohistochemical chase experiments administering biotinylated AP- 1 oligos into arthritic mice, on the other hand, also showed that doublestranded DNA oligonucleotides shorter than 24-mer appeared easily degradable before they reached the synovium. This is in agreement with the result of transfection study indicating that shorter AP-1m or AP-s oligos are less efficient in inhibiting gene transcription through the promoter of Col-TRE/TK CAT. It appears that nucleotides besides the core AP-1 sequence are important not only structurally for the binding of AP-1 onto DNA, but also for the stability against digestion by nucleases.

Although we used double-stranded DNA oligonucleotides to specifically compete for the binding of AP-1 in vivo at the promoter AP-1 consensus binding sites, the use of doublestranded DNA is by no means unique. Previous studies indicate that short double-stranded DNA oligonucleotides can be incorporated into cell nuclei in the in vitro culture condition (33). Expression vectors can also exert their effect in vivo when administered in combination with liposomes (34). We did not use liposomes because our double-stranded DNA worked fairly well without them. Instead, we rather intentionally avoided 'too much effect' of AP-1 oligos for two reasons: first, we considered that the reason why AP-1 oligos inhibited arthritic joint destruction without significant untoward effect must reside in the fact that AP-1 oligos were easily degradable and their effect was transient. Assuming that c-fos/AP-1 activity in the rheumatoid joint is 10 -fold higher than in normal tissue (14) and that AP-1 oligos inhibit cellular AP-1 activity by $50 \%$, the net decrease of AP-1 activity in rheumatoid joint and normal tissue is 5 and 0.5 , respectively. The $50 \%$ decrease, which is transient as well, should not be harmful to normal cell function; however, the decrease of AP-1 activity in inflamed joints from 10- to 5-fold is significant. AP-1 oligos were indeed without significant untoward effect as far as our animal studies indicated. Second, we assumed that only a small amount of AP-1 oligos might be required for the inhibition of arthritis in vivo, possibly by a chain reaction between cytokines and enzymes ongoing in arthritic joints $(1,4,35)$. Since almost all cytokines and matrix degrading proteinases important in arthritis contain AP-1 consensus sequences in their promoter $(6,35)$, even a small decrease of gene transcription for each component, as shown in this study, could lead in succession to a considerable decrease of total cytokine and enzyme activities in inflamed joints.

We found that AP-1 oligos inhibited joint destruction more efficiently than inflammatory cell infiltration. This is consistent with the previous finding that arthritic joint destruction induced in $\mathrm{H} 2$-c-fos transgenic mice was without lymphocyte infiltration to the joint, in which the majority of cells invading the extensively eroded joint tissue was mesenchymal synovial cells that had a potential to invade cartilage matrix when cultured in vitro (7). O'Sullivan et al. (8) have shown that primary lesion of the joint destruction occurring in the spontaneous arthritis of autoimmune MRL/l mice is more closely related to the presence of transformed-appearing proliferating synovial cells than to the presence of subsynovial or periarticular inflammation. Schaible et al. (9) reported that lymphocytes were not necessarily required for the arthritic joint destruction of lyme borreliosis (9). Moreover, previous studies indicated that expression of c-fos gene was weak but constant in mesenchy- 
mal cells, and c-fos/c-jun heterodimer (AP-1) was essentially important for expression of mRNA for collagenase and stromelysin as well as IL-1 $\beta$, IL- 6 , and TNF $\alpha$ that were produced mainly from mesenchymal synovial cells (1, 2, 6, 35-37). These findings suggest that arthritic joint destruction involving mesenchymal synovial cells is to a certain extent an independent process distinct from $\mathrm{T}$ cell-centered antigen-specific immune responses.

The previous finding that features characteristic to rheumatoid joint destruction including synovial overgrowth and bone resorption were experimentally produced by augmenting c-fos gene expression $(7,10-13)$ and the present finding that arthritic joint destruction was specifically inhibited by the oligonucleotides containing the AP-1 consensus sequence would suggest that activation of the c-fos gene fulfills a condition that is necessary and sufficient for arthritic joint destruction. Since expression of the c-fos gene is increased in RA (14), the c-fos/ AP-1 signal should be important in arthritic joint destruction.

\section{Acknowledgments}

We thank Dr. Edward B. Ziff at New York University for useful discussion and help, Dr. Michael Karin at the University of California, Department of Pharmacology for Col-TRE/TK CAT plasmids, Dr. Haku Hotta at Kobe University for H-ras-transformed NIH3T3 cells, and Dr. Kakuji Torigoe at Hayashibara Biochemical Institute, Inc. for some PCR primers.

\section{References}

1. Harris, E.D., Jr. 1990. Rheumatoid arthritis. Pathophysiology and implications for the therapy. N. Engl. J. Med. 322:1277-1289.

2. Zvaifler, N.J., and G.S. Firestein. 1994. Pannus and pannocytes. Arthritis Rheum. 37:783-787.

3. Auger, I., J.M. Escola, J.P. Gorvel, and J. Roudier. 1996. HLA-DR4 and HLA-DR10 motifs that carry susceptibility to rheumatoid arthritis bind 7-kD heat shock proteins. Nat. Med. 2:306-310.

4. Koopman, W.J. 1994. The future of biologics in the treatment of rheumatoid arthritis. Semin. Arthritis Rheum. 23(6 Suppl. 2):50-58.

5. Shiozawa, S., K. Shiozawa, and T. Fujita. 1983. Morphologic observations in the early phase of the cartilage-pannus junction. Arthritis Rheum. 26:472478.

6. Angel, P., and M. Karin. 1991. The role of Jun, Fos and the AP-1 complex in cell-proliferation and transformation. Biochim. Biophys. Acta. 1072:129-157.

7. Shiozawa, S., Y. Tanaka, T. Fujita, and T. Tokuhisa. 1992. Destructive arthritis without lymphocyte infiltration in $\mathrm{H} 2$-c-fos transgenic mice. J. Immunol. 148:3100-3104

8. O'Sullivan, F.X., H.G. Fassbender, S. Gay, and W.J. Koopman. 1985. Etiopathogenesis of the rheumatoid arthritis-like disease in MRL/l mice. I. The histomorphologic basis of joint destruction. Arthritis Rheum. 28:529-536.

9. Schaible, U.E., S. Gay, C. Museteanu, M.D. Kramer, G. Zimmer, K. Eichmann, U. Museteanu, and M.M. Simon. 1990. Lyme borreliosis in the severe combined immunodeficiency (scid) mouse manifested predominantly in the joints, heart, and liver. Am. J. Pathol. 137:811-820.

10. Kuroki, Y., S. Shiozawa, R. Yoshihara, and H. Hotta. 1993. The contribution of human c-fos DNA to cultured synovial cells: a transfection study. $J$. Rheumatol. 20:422-428.

11. Kuroki, Y., S. Shiozawa, T. Sugimoto, and T. Fujita. 1992. Constitutive expression of c-fos gene inhibits type 1 collagen synthesis in transfected osteoblasts. Biochem. Biophys. Res. Commun. 182:1389-1394.

12. Kuroki, Y., S. Shiozawa, T. Sugimoto, M. Kanatani, H. Kaji, A. Miyauchi, and K. Chihara. 1994. Constitutive c-fos expression in osteoblastic MC3T3E1 cells stimulates osteoclast maturation and osteoclastic bone resorption. Clin. Exp. Immunol. 95:536-539.

13. Miyauchi, A., Y. Kuroki, M. Fukase, T. Fujita, K. Chihara, and S. Shiozawa. 1994. Persistent expression of proto-oncogene c-fos stimulates osteoclast differentiation. Biochem. Biophys. Res. Commun. 205:1547-1555.

14. Trabandt, A., W.K. Aicher, R.E. Gay, V.P. Sukhatme, H.G. Fass- bender, and S. Gay. 1992. Spontaneous expression of immediately-early response genes c-fos and erg-1 in collagenase-producing rheumatoid synovial fibroblasts. Rheumatol. Int. 12:53-59.

15. Wooley, P.H. 1988. Collagen-induced arthritis in the mouse. Methods Enzymol. 162:361-373.

16. Sato, H., M. Kita, and M. Seiki. 1993. v-Src activates the expression of 92-kDa type IV collagenase gene through the AP-1 site and the GT box homologous to retinoblastoma control elements. J. Biol. Chem. 268:23460-23468.

17. Bjork, J., and S. Kleinau. 1989. Paradoxical effects of LS-2616 (Linomide) treatment in the type II collagen arthritis model in mice. Agents Actions. 27:319-321.

18. Yoshihara, R. S. Shiozawa, T. Fujita, and K. Chihara. 1993. Gamma interferon is produced by human natural killer cells but not T cells during Staphylococcus aureus stimulation. Infect. Immun. 61:3117-3122.

19. Chomczynski, P., and N. Sacchi. 1987. Single-step method of RNA isolation by acidic guanidium thiocyanate-phenol-chloroform extraction. Anal. Biochem. 162:156-159.

20. Telford, J.T. G. Macchia, A. Massone, V. Carinci, E. Palla, and M. Melli. 1986. The murine interleukin-1 gene: structure and evolution. Nucleic Acids Res. 14:9955-9963.

21. Tanabe, O., S. Akira, T. Kamiya, G.G. Wong, T. Hirano, and T. Kishimoto. 1988. Genomic structure of the murine IL-6 gene. High degree conservation of potential regulatory sequences between mouse and human. J. Immunol. 141:3875-3881.

22. Pennica, D., J.S. Hayflick, T.S. Bringman, M.A. Palladino, and D.V. Goeddel. 1985. Cloning and expression in Escherichia coli of the cDNA for murine tumor necrosis factor. Proc. Natl. Acad. Sci. USA. 82:6060-6064.

23. Reponen, P., C. Sahlberg, P. Huhtala, T. Hurskainen, I. Thesleff, and K. Tryggvason. 1992. Molecular cloning of murine 72-kDa type IV collagenase and its expression during mouse development. J. Biol. Chem. 267:7856-7862.

24. Hammani, K., P. Henriet, and Y. Eeckhout. 1992. Cloning and expression of the cDNA encoding mouse stromelysin 1. Gene (Amst.). 120:321-322.

25. Graubert, T., J. Johnston, and N. Behliner. 1993. Cloning and expression of the cDNA encoding mouse neutrophil gelatinase: demonstration of coordinate secondary granule protein gene expression during terminal neutrophil maturation. Blood. 82:3192-3197.

26. Sabath, D.E., H.E. Broome, and M.B. Prystowsky. 1990. Glyceraldehyde-3-phosphate dehydrogenase mRNA is a major interleukin-2-induced transcript in a cloned T-helper lymphocyte. Gene (Amst.). 91:185-191.

27. Chelly, J., J.-C. Kaplan, P. Maire, S. Gautron, and A. Kahn. 1988. Transcription of the dystrophin gene in human muscle and non-muscle tissues. $\mathrm{Na}$ ture (Lond.). 333:858-860

28. Wang, C.-N.J., K.Y. Wu, and H.-T. Wang. 1995. Quantitative PCR using the amplisensor assay. In PCR Primer: A Laboratory Manual. C.W. Dieffenbach and G.S. Dveksler, editors. Cold Spring Harbor Laboratory Press, New York. 193-196.

29. Hotta, S., H. Miyamoto, H. Hara, N. Takahashi, and M. Homma. 1992. Genomic structure of the ME491/CD63 antigen gene and functional analysis of the 5 '-flanking regulatory sequences. Biochem. Biophys. Res. Commun. 185: 436-442.

30. Angel, P., M. Imagawa, R. Chiu, B. Stein, R.J. Imbra, H.J. Rahmsdorf, C. Jonat, P. Herrlich, and M. Karin. 1987. Phorbol ester-inducible genes contain a common cis element recognized by a TPA-modulated trans-acting factor. Cell. 49:729-739.

31. Gorman, C.M., L.F. Moffat, and B.H. Howard. 1982. Recombinant genomes which express chloramphenicol acetyltransferase in mammalian cells. Mol. Cell. Biol. 2:1044-1051.

32. Porsch, P., S. Merkelbach, J. Gehlen, and M. Fladung. 1993. The nonradioactive chloramphenicol acetyltransferase-enzyme-linked immunosorben assay test is suited for promoter activity studies in plant protoplasts. Anal. Biochem. 211:113-116.

33. Kerr, L.D., J.D. Holt, and L.M. Matrisian. 1988. Growth factors regulate transin gene expression by c-fos dependent and c-fos independent pathways. Science (Wash. DC). 242:1424-1427.

34. Zhu, N., D. Liggitt, Y. Liu, and R. Debs. 1993. Systemic gene expression after intravenous DNA delivery into adult mice. Science (Wash. DC). 261:209211.

35. Shiozawa, S., and T. Tokuhisa. 1992. Contribution of synovial mesenchymal cells to the pathogenesis of rheumatoid arthritis. Semin. Arthritis Rheum. 21:267-273.

36. Schønthal, A.P., P. Herrlich, H.J. Rahmsdorf, and H. Ponta. 1988. Requirement for fos gene expression in the transcriptional activation of collagenase by other oncogenes and phorbol esters. Cell. 54:325-334.

37. Maini, R.N., M.J. Elliott, F.M. Brennan, R.O. Williams, C.O. Chu, E. Paleolog, P.J. Charies, P.C. Taylor, and M. Feldmann. 1995. Monoclonal antiTNF alpha antibody as a probe of pathogenesis and therapy of rheumatoid disease. Immunol. Rev. 144:195-223. 